\title{
PHYSICAL AND CHEMICAL CHARACTERISTICS OF PALM OIL-BASED SOLID FRACTIONS WITH MORE THAN 20\% OF TRIPALMITOYL- GLYCEROL FROM MALAYSIAN FRACTIONATION PLANTS
}

SIVARUBY KANAGARATNAM*; ZALIHA OMAR* and MISKANDAR MAT SAHRI ${ }^{\star}$

\begin{abstract}
The varied triacylglycerol composition of palm oil-based solid fractions (POSF) gives unique characteristics to its fractions. The potential to develop specific fractions for specific functionalities is very vital to the Malaysian palm oil industry in order to widen the usage of POSF for food formulations. Fractions with higher amounts of trisaturated triacylglycerols are excellent structural fats for food formulations. This compilation was directed towards obtaining the primary information on the characteristics of POSF available in Malaysia containing more than $20 \%$ of tripalmitoyl-glycerol. This information will be vital in guiding food formulators on the wide options of structural fats available in Malaysia. Commercially available POSF were collected and characterised. Their triacylglycerol composition, fatty acid composition, iodine value, dropping point, and solid fat content were determined. The results showed that the characteristics of the POSF were greatly influenced by the amount of tripalmitoyl-glycerol (PPP) present in the fractions. The amount of PPP had a substantial impact on the dropping point and the solid fat content profile. Hence, fractions were categorised according to their percentage of PPP to provide groupings with specific physical and chemical characteristics. The percentage of PPP in Group PPP 1 was 20\% to 30\%, PPP 2 was 40\% to 50\%, PPP 3 was 55\% to 60\%, PPP 4 was $62 \%$ to $63 \%$ and PPP 5 was $67 \%$ to $68 \%$. The range of dropping points recorded for $P P P 1$ was $54^{\circ} \mathrm{C}$ to $56^{\circ} \mathrm{C}, P P P 2$ was $59^{\circ} \mathrm{C}$ to $60^{\circ} \mathrm{C}$, PPP 3 was $61^{\circ} \mathrm{C}$ to $62^{\circ} \mathrm{C} P P P 4$ was $62.2^{\circ} \mathrm{C}$ to $62.4^{\circ} \mathrm{C}$ and PPP 5 was $63.1^{\circ} \mathrm{C}$ to $63.7^{\circ} \mathrm{C}$. The range of solid fat content at $30^{\circ} \mathrm{C}$ recorded for PPP 1 was $44 \%$ to 54\%, PPP 2 was $78 \%$ to $82 \%$, PPP 3 was $86 \%$ to $89 \%$, PPP 4 was $90 \%$ to $91 \%$ and PPP 5 was $91 \%$ to $93 \%$. This compilation shows the extensive range of POSF which are able to provide a specific functionality to facilitate their specialised application in food formulations that are commercially available in Malaysia.
\end{abstract}

Keywords: palm oil-based solid fractions, structural fats, tripalmitoyl-glycerol, solid fat content.

Date received: 8 September 2017; Sent for revision: 14 September 2017; Received in final form: 12 January 2018; Accepted: 5 July 2018.

\section{INTRODUCTION}

The primary role of fats in foods is to impart sensory attributes such as creaminess, mouthfeel,

\footnotetext{
Malaysian Palm Oil Board,

6 Persiaran Institusi, Bandar Baru Bangi,

43000 Kajang, Selangor, Malaysia.

E-mail: sivaruby@mpob.gov.my
}

enhancement of food flavours, spreadability, lubrication, cohesiveness and structure. Solid fats provide the crucial characteristics such as structure, texture and firmness in food products. In many food applications, the fat component exists in a semi-solid state (soft homogenous solids) which are bonded by fat crystal network facilitated by solid fats. These solid fats consist mainly of saturated 
triacylglycerols and are classified as structural fats (Marangoni, 2005; Narine and Marangoni, 1999; 2002). The solid fats play a vital role to provide the structural firmness and solid-like behaviour in food products with high percentage of fats (Omonov et al., 2010). The most conventional approach to provide structure in margarines and spreads are by incorporating solid fats (Kloek et al., 2000; Flöter et al., 2006). Solid fats (structural fats) are responsible for crystal structure and crystal network formation in margarines and spreads (Pernetti et al., 2007; Rogers, 2009).

Driven by consumer demand, natural plant fats, have become the preferred option across the food processing industry compared to animal and hydrogenated fats. Palm oil and its diversified range of palm oil-based solid fractions (POSF) are excellent natural solid fats which are able to cater for a wide range of food products. POSF are extensively used in manufacturing shortenings, margarines, confectionary fats, frying fats, milk fat replacers, and ice cream fats which in turn are used to make a wide range of products including breads, biscuits, cakes, cookies, chocolates, ice creams and pastries (Lai et al., 1998; Ming et al., 1999). POSF are highly recommended as they are cost efficient, easily available, have high solid fat content (SFC), free of trans fatty acids and have high oxidative stability (long shelf-life) (Braipson-Danthine and Gibon, 2007).

Fractionation of oils and fats is a separation process, which involves fractional crystallisation of oils and fats by controlled cooling (Liu et al., 2010). This process involves specific crystallisation of triacylglycerols to form solid fats, followed by filtration processes to separate the solid fats from the liquid fractions (Kellens et al., 2007). The fractionation process is based on the ability of the triacylglycerols to produce crystals under specific cooling conditions. The ability of the triacylglycerols to produce crystals depends on their melting points, degree of saturation, molecular weight and difference in solubility of the solid triacylglycerols in the liquid phase (Braipson-Danthine and Gibon, 2007; Kellens et al., 2007).

Palm oil is the most widely fractionated oil in the world due to its diverse triacylglycerol composition, boasting an equal amount of unsaturated to saturated fatty acid composition (Deffense, 1985; Vuillequez et al., 2010). This unique composition of palm oil opens endless opportunity in the production of liquid oils and solids fats. Dry fractionation process separates palm oil into two fractions, liquid fraction (palm olein) and palm solid fraction. Palm olein is rich in low melting point triacylglycerols and is used mainly as cooking oil (Norizzah et al., 2004; Ahmad Tarmizi and Ismail, 2008). Whereas POSF contains substantial amounts of saturated triacylglycerols which provide solid fraction with a higher melting point (Pande and Akoh, 2013). The continuous advancement in fractionation technology has led the way to produce POSF with a high degree of selectivity. Fractionation can be carried out in single or multiple steps, giving rise to a wide range of POSF. The POSF were subjected to double or even triple fractionation to obtain POSF with an increasing enrichment of a specific triacylglycerol for special applications. These multi stage fractionation routes are continuously improved by the industry resulting in very specialised and high valued POSF (Calliauw et al., 2007).

This characterisation work was directed toward compiling basic information on the physical and chemical characteristics of different POSF. This compilation of information will be of great interest to food formulators as it will provide a rather comprehensive information on the wide range of natural POSF available in Malaysia. Commercially available POSF were evaluated for their triacylglycerol composition, fatty acid composition, iodine value, dropping point and SFC.

\section{MATERIALS}

POSF samples were obtained from local fractionation plants. The POSF obtained were mainly produced by the dry fractionation process. The POSF collected in this study were from diversely varied processing conditions applied by industry, single or multi-stage fractionation [hydrogenated and interesterified (chemical or enzymatic) POSF were excluded from this study].

\section{METHODS}

The characteristics of POSF were based on their triacylglycerol composition, fatty acid composition, iodine value, dropping point, and solid fat content, hence these analyses were carried out.

\section{Triacylglycerol Composition Analysis}

The POSF samples were prepared by dissolving $0.015 \mathrm{~g} \mathrm{litre}^{-1}$ in acetone. The samples were then filtered through a $0.2 \mu \mathrm{m}$ nylon membrane filter to remove any solid impurities. The triacylglycerol profiles were determined using high performance liquid chromatography (HPLC) (Agilent 1100 Series, USA). The $10 \mu \mathrm{l}$ of sample was injected into two Purospher ${ }^{\circledR}$ STAR RP-18 endcapped column (25 $\mathrm{cm}$ length $\times 4 \mathrm{~mm}$ i.d with of $5 \mu \mathrm{m}$ particle size) (Merck KGaA, Darmtadt, Germany) connected in series. The column was kept in an oven at $30^{\circ} \mathrm{C}$. The mobile phase used was acetone: acetonitrile $(75: 25 \% \mathrm{vol} / \mathrm{vol})$, at a flow rate of $1.0 \mathrm{ml} \mathrm{min}{ }^{-1}$ under isocratic conditions. The individual peaks 
were identified by a refractive index detector and the total run time was $45 \mathrm{~min}$ per sample. The chromatograms were identified by comparing retention times with standards and quantified using the area normalisation method (Ramli et al., 2008). All analysis was carried out in triplicates.

\section{Iodine Value}

Iodine value denotes the degree of unsaturation of fatty acids in oils and fats. Determination of IV was carried out according to MPOB Test Method p3.2: 2004 (Kuntom et al., 2005). The $20 \mathrm{~g}$ of totally melted and homogenised sample and $20 \mathrm{ml}$ of solvent (1:1 cyclohexane: glacial acetic acid) were weighed into a conical glass flask fitted with a round glass stopper. The $25 \mathrm{ml}$ of Wijs reagent was added, the stopper was replaced, the solution swirled by hand and placed in a dark for room for $1 \mathrm{hr}$. A blank test was prepared with the solvent and reagent, omitting the test portion. At the end of the reaction time, $20 \mathrm{ml}$ of potassium iodide and $150 \mathrm{ml}$ of water were added. The solution was then titrated with standard sodium thiosulphate solution. The blank test was similarly treated and titrated. Calculation of the ioden value was carried out, the iodine values were expressed as $\mathrm{g}$ of $\mathrm{I}_{2} / 100 \mathrm{~g}$ of oil (Aini et al., 2010). All analysis was carried out in triplicates.

\section{Dropping Point}

The dropping point indicates the temperature where the frozen POSF becomes liquid and is able to flow. Determination of dropping point was carried out in accordance to MPOB Test Method f1.2: 2004 (Kuntom et al., 2005). A Mettler Toledo dropping point analysing system with central processor FP90 (AG, Schwerzenvach, Switzerland) was used to determine the dropping point of the POSF. The sample cup (inner diameter $2.8 \mathrm{~mm}$ Mettler No. 18732) was placed in the freezer (below $-5^{\circ} \mathrm{C}$ ) for a minimum of $10 \mathrm{~min}$. The POSF sample was melted, homogenised and filled into the sample cup. The filled cup was kept in the freezer for $15 \mathrm{~min}$. The dropping point analyser was set at $10^{\circ} \mathrm{C}$ below the expected dropping point. The heating rate was set at

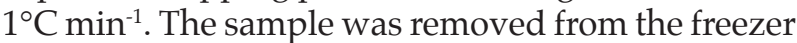
and immediately placed into the dropping point measuring cell. The dropping point was recorded. All analysis was carried out in triplicates.

\section{Fatty Acid Composition}

Fatty acid composition (FAC) was determined as fatty acid methyl esters (FAME). The samples $(0.05 \mathrm{~g})$ were weighed and dissolved in $1 \mathrm{ml}$ hexane. The mixture was then added with sodium methoxide solution $\left[0.2 \mathrm{ml}\right.$ of $\mathrm{NaOCH}_{3}(2 \mathrm{M})$ in anhydrous methanol] and then mixed for $1 \mathrm{~min}$ with a vortex mixer. After sedimentation of sodium glycerolate, $1 \mu \mathrm{m}$ of clear supernatant was injected into Rtx 2330 fused silica capillary column $(60 \mathrm{~m}$ $\times 0.25 \mathrm{~mm} \times 0.25 \mu)($ Restex Corporation, USA) and analysed using a Burker gas chromatography system Model 430-GC (Burker Daltonics, CA, USA) equipped with a flame ionisation detector (FID) and Galaxie Chromatography Data System. Injection and detection temperatures were set at $240^{\circ} \mathrm{C}$. The oven temperature was set at $190^{\circ} \mathrm{C}$. The column temperature was isothermal at $185^{\circ} \mathrm{C}$. The carrier gas was helium with flow rate of $1 \mathrm{ml} \mathrm{min}^{-1}$. The peaks were identified by comparing retention times with FAME standards and quantified using peak area normalisation methods. All analysis was carried out in triplicates.

\section{Solid Fat Content}

Solid fat content (SFC) denotes the amount of solid present at a specific temperature. Determination of SFC was performed according to MPOB Test Method (MPOB p4.8: 2004) (Kuntom et al., 2005). The SFC was measured with Bruker Minispec PC 120 pulse. Samples were totally melted at $80^{\circ} \mathrm{C}$ to erase all crystal memory. The totally melted samples were homogenised and filled into tubes $(10 \mathrm{~mm}$ o.d x $75 \mathrm{~mm}$ length) up to $3 \mathrm{~cm}$ in height. The samples were tempered at $70^{\circ} \mathrm{C}$ in a water bath for $30 \mathrm{~min}$, before chilling at $0^{\circ} \mathrm{C}$ for $90 \mathrm{~min}$. These tubes were conditioned in pre-equilibrated thermostated baths for $30 \mathrm{~min}$ prior to the measurement. The measuring temperatures were $0^{\circ} \mathrm{C}, 5^{\circ} \mathrm{C}, 10^{\circ} \mathrm{C}, 15^{\circ} \mathrm{C}, 20^{\circ} \mathrm{C}, 25^{\circ} \mathrm{C}$, $30^{\circ} \mathrm{C}, 35^{\circ} \mathrm{C}, 40^{\circ} \mathrm{C}, 45^{\circ} \mathrm{C}, 50^{\circ} \mathrm{C}, 55^{\circ} \mathrm{C}, 60^{\circ} \mathrm{C}, 65^{\circ} \mathrm{C}$ and $70^{\circ} \mathrm{C}$. The direct method was employed for the measurements. All analysis was carried out in triplicates.

\section{RESULTS AND DISCUSSION}

Triacylglycerol composition, FAC, iodine value, dropping point, and SFC of the commercial POSF were determined and the grouping of the POSF were based on these analyses results. The characteristics of the POSF were greatly influenced by the triacylglycerol composition which was reflected in the corresponding FAC, iodine value, dropping point, and SFC. In the formulation of high fat foods such as margarines, shortenings, cooking fats, vanaspati and spreads the SFC profile plays a crucial role in the selection of fats. Hence, the grouping of the POSF in this compilation was based on the factor that expressively influenced the SFC in order to facilitate the selection of POSF for food formulations. Saturated triacylglycerol implicitly influences the SFC profile of fats (Okawachi et al., 1985). POSF contains saturated triacylglycerol such as tripalmitoyl-glycerol (PPP), dipalmitoyl-stearoyl- 
glycerol (PPS), distearoyl-palmitoyl-glycerol (PSS) and dipalmitoyl-myristoyl-glycerol (MPP) which dominate the SFC profiles. The amount of PPP in the POSF were substantially higher than the other saturated triacylglycerol, hence this relates to the prevailing influence of PPP on the SFC of the POSF, hence PPP was used as the crucial factor in the grouping of the POSF. The percentage of PPP in Group PPP 1 was $20 \%$ to $30 \%$, PPP 2 was $40 \%$ to $50 \%$, PPP 3 was $55 \%$ to $60 \%$, PPP 4 was $62 \%$ to $63 \%$ and PPP 5 was $67 \%$ to $68 \%$. These groups were discussed at length in the following segments to provide a better understanding of the physical and chemical characteristic of the POSF.

\section{POSF of Group PPP 1 with $20 \%$ to $30 \%$ of PPP Content}

POSF of Group PPP 1 were obtained through single fractionation of palm oil. Table 1 shows that the trisaturated triacylglycerols composition ranged from $29.36 \%$ to $35.43 \%$ with $23.08 \%$ to $28.43 \%$ of PPP. The monounsaturated triacylglycerols ranged from $39.51 \%$ to $45.00 \%$, with POP content ranging from $28.11 \%$ to $32.74 \%$. The percentage of diunsaturated and triunsaturated triacylglycerols ranged from $19.24 \%$ to $22.38 \%$ and $4.99 \%$ to $5.39 \%$ respectively. The dropping points of the POSF in group PPP 1 were in the range of $54.3^{\circ} \mathrm{C}$ to $56.4^{\circ} \mathrm{C}$. The corresponding iodine value obtained were 31.43 to $34.48 \mathrm{~g}$ of $\mathrm{I}_{2} / 100 \mathrm{~g}$ of oil, as shown in Table 2. It was reported by Kellens et al. (2007) that palm stearin with PPP percentage of $26.5 \%$ gave an iodine value of $34.4 \mathrm{I}_{2} / 100 \mathrm{~g}$ (Kellens et al., 2007). It was also reported that palm stearin with an iodine value of $32 \mathrm{I}_{2} / 100 \mathrm{~g}$ obtained via single fractionation gave a melting point of $54^{\circ} \mathrm{C}$ (Kellens and Hendrix, 2000). The percentage of polyunsaturated fatty acids ranged from $5.0 \%$ to $7.0 \%$.

The results also indicates that the percentage of monounsaturated fatty acids which consist of mostly oleic acid were $25.12 \%$ to $27.22 \%$. The percentage of saturated fatty acids were the highest, ranging from $65.95 \%$ to $69.36 \%$ with $58.98 \%$ to $62.99 \%$ of palmitic acid as shown in Table 2. These fractions are good source of palmitic acid. Zou et al. studied the synthesis of human milk fat substitutes by combining methods such as enzymatic acidolysis with blending of various oils such as basa catfish oil, sesame oil, flaxseed oil, sunflower oil, palm kernel oil, palm stearin (C16:0 of 61\%), alga oil and microbial oil. Palm stearin was included in the oil blends as the source of palmitic acid (Zou et al., 2016).

The SFC profiles of POSF in group PPP 1 exhibited similar trends as shown in Figure 1. The SFC profile of this group of solids did not exhibit a sharp drop at the temperatures investigated but decreased in a gradual manner with a decrease of
$15 \%$ to $20 \%$ solids per $10^{\circ} \mathrm{C}$ increase between $10^{\circ} \mathrm{C}$ to $50^{\circ} \mathrm{C}$. The percentages of solids detected at $50^{\circ} \mathrm{C}$ for this group of POSF were as high as $12 \%$ to $17 \%$. The high percentage of trisaturated triacylglycerols with high melting points has led to high solid fat content values at all the evaluated temperatures (Zhou et al., 2010). The percentage of trisaturated triacylglycerols varied from $29 \%$ to $35 \%$ with $23 \%$ to $28 \%$ of PPP present. Hence, these fractions are very suitable to be used as backbone structures in the formulation of margarines and shortenings (used in non-refrigerated storage conditions).

\section{POSF of Group PPP 2 with $40 \%$ to $50 \%$ of PPP Content}

POSF in Group PPP 2 were obtained through fractionation of POSF of IV 30. The trisaturated triacylglycerols ranged from $51.99 \%$ to $61.34 \%$ with PPP content of $42.35 \%$ to $48.80 \%$ as shown in Table 3 . The monounsaturated triacylglycerols ranged from $24.84 \%$ to $36.17 \%$, with POP content ranging from $17.80 \%$ to $26.70 \%$. The percentage of diunsaturated and triunsaturated triacylglycerol ranged from $6.15 \%$ to $10.67 \%$ and $4.04 \%$ to $5.81 \%$ respectively. The dropping points of the POSF in Group PPP 2 were also strongly influenced by the content of trisaturated triacylglycerols as the dropping points recorded for this group of POSF were in the range of $59.0^{\circ} \mathrm{C}$ to $60.0^{\circ} \mathrm{C}$. The corresponding iodine values obtained were 17.94 to $20.60 \mathrm{I}_{2} / 100 \mathrm{~g}$ as shown in Table 4.

The percentage of polyunsaturated fatty acids ranged from $3.19 \%$ to $3.98 \%$. The percentage of monounsaturated fatty acids which consist of mostly oleic acid were $14.21 \%$ to $16.45 \%$. The percentage of saturated fatty acid was the highest ranging from $80.29 \%$ to $82.60 \%$ with $72.23 \%$ to $76.19 \%$ of palmitic acid as shown in Table 4. Structural fat for the production of margarine was produced by interesterification of non-hydrogenated high melting palm solid fraction and non-hydrogenated palm kernel fraction. The requirement of hard palm fraction used in this structural fat was more than $70 \%$ of palmitic acid. The palmitic acid contributes to the structure of the hard stock (Ullanoormadam, 2004).

POSF of Group PPP 2 exhibited high SFC profiles below $20^{\circ} \mathrm{C}$, with SFC values above $90 \%$. The percentage of SFC ranged from $88 \%$ to $90 \%$ at $20^{\circ} \mathrm{C}$ and decreased $5 \%$ in SFC with the increase in temperature to $83 \%$ to $87 \%$ at $25^{\circ} \mathrm{C}$. The SFC decreased approximately $7 \%$ to $8 \%$ for the corresponding increase of $10^{\circ} \mathrm{C}$ from $30^{\circ} \mathrm{C}$ to $40^{\circ} \mathrm{C}$ as shown in Figure 2. The SFC values of these POSF were higher than $50 \%$ at $40^{\circ} \mathrm{C}$ with readings as high as $56 \%$ to $67 \%$. The SFC decreased approximately $10 \%$ for the corresponding increase of $10^{\circ} \mathrm{C}$ from $40^{\circ} \mathrm{C}$ to $50^{\circ} \mathrm{C}$, the SFC values were $35 \%$ to $47 \%$ at $50^{\circ} \mathrm{C}$. The $\mathrm{SFC}$ decrease $15 \%$ from $50^{\circ} \mathrm{C}$ to $55^{\circ} \mathrm{C}$ with $\mathrm{SFC}$ value 


\begin{tabular}{|c|c|c|c|c|c|c|c|}
\hline \multicolumn{8}{|c|}{$\begin{array}{l}\text { TABLE 1. TRIACYLGLYCEROL COMPOSITION OF PALM OIL-BASED SOLID FRACTIONS } \\
\text { OF PPP } 1 \text { WITH } 20 \% \text { TO } 30 \% \text { OF PPP CONTENT }\end{array}$} \\
\hline & 1 & 2 & 3 & 4 & 5 & 6 & 7 \\
\hline LLL & $0.26 \pm 0.00$ & $0.23 \pm 0.00$ & $0.14 \pm 0.01$ & $0.17 \pm 0.03$ & $0.25 \pm 0.01$ & $0.13 \pm 0.00$ & $0.18 \pm 0.00$ \\
\hline PLL & $1.48 \pm 0.01$ & $1.39 \pm 0.01$ & $1.09 \pm 0.02$ & $1.25 \pm 0.03$ & $1.17 \pm 0.07$ & $0.99 \pm 0.03$ & $1.15 \pm 0.03$ \\
\hline MLP & $0.39 \pm 0.05$ & $0.57 \pm 0.36$ & $0.56 \pm 0.35$ & $0.39 \pm 0.15$ & $0.28 \pm 0.07$ & $0.39 \pm 0.01$ & $0.46 \pm 0.01$ \\
\hline OOL & $1.06 \pm 0.02$ & $0.84 \pm 0.03$ & $1.09 \pm 0.21$ & $0.90 \pm 0.04$ & $1.05 \pm 0.02$ & $0.81 \pm 0.03$ & $0.90 \pm 0.01$ \\
\hline POL & $5.62 \pm 0.09$ & $4.65 \pm 0.17$ & $5.40 \pm 0.23$ & $4.50 \pm 0.17$ & $5.23 \pm 0.06$ & $4.24 \pm 0.05$ & $4.31 \pm 0.08$ \\
\hline PLP & $7.18 \pm 0.10$ & $5.93 \pm 0.02$ & $6.10 \pm 0.11$ & $6.58 \pm 0.49$ & $6.70 \pm 0.25$ & $5.55 \pm 0.13$ & $5.88 \pm 0.18$ \\
\hline MPP & $1.24 \pm 0.02$ & $1.44 \pm 0.13$ & $1.63 \pm 0.06$ & $1.27 \pm 0.16$ & $1.14 \pm 0.17$ & $1.31 \pm 0.02$ & $1.01 \pm 0.01$ \\
\hline OOO & $3.88 \pm 0.05$ & $3.93 \pm 0.16$ & $3.77 \pm 0.05$ & $3.93 \pm 0.34$ & $4.00 \pm 0.07$ & $4.08 \pm 0.05$ & $4.30 \pm 0.04$ \\
\hline POO & $14.02 \pm 0.04$ & $12.42 \pm 0.15$ & $12.95 \pm 0.13$ & $11.86 \pm 0.12$ & $12.71 \pm 0.13$ & $12.91 \pm 0.1$ & $12.54 \pm 0.05$ \\
\hline POP & $30.52 \pm 0.04$ & $32.74 \pm 0.11$ & $30.59 \pm 0.22$ & $30.56 \pm 0.07$ & $28.11 \pm 0.13$ & $29.86 \pm 0.21$ & $28.90 \pm 0.14$ \\
\hline PPP & $23.08 \pm 0.02$ & $23.66 \pm 0.13$ & $24.82 \pm 0.14$ & $26.82 \pm 0.07$ & $26.97 \pm 0.05$ & $26.99 \pm 0.08$ & $28.43 \pm 0.02$ \\
\hline $\mathrm{SOO}$ & $1.26 \pm 0.04$ & $0.97 \pm 0.02$ & $1.07 \pm 0.10$ & $1.04 \pm 0.14$ & $1.23 \pm 0.14$ & $1.27 \pm 0.01$ & $1.25 \pm 0.03$ \\
\hline POS & $4.46 \pm 0.10$ & $5.30 \pm 0.02$ & $4.65 \pm 0.07$ & $4.54 \pm 0.34$ & $4.09 \pm 0.11$ & $5.01 \pm 0.01$ & $4.31 \pm 0.02$ \\
\hline PPS & $4.51 \pm 0.07$ & $4.73 \pm 0.17$ & $4.97 \pm 0.16$ & $5.16 \pm 0.01$ & $5.78 \pm 0.03$ & $5.20 \pm 0.05$ & $5.39 \pm 0.01$ \\
\hline SOS & $0.51 \pm 0.07$ & $0.46 \pm 0.01$ & $0.52 \pm 0.01$ & $0.42 \pm 0.02$ & $0.34 \pm 0.04$ & $0.60 \pm 0.01$ & $0.38 \pm 0.01$ \\
\hline PSS & $0.53 \pm 0.04$ & $0.50 \pm 0.01$ & $0.66 \pm 0.03$ & $0.61 \pm 0.05$ & $0.94 \pm 0.09$ & $0.67 \pm 0.03$ & $0.60 \pm 0.0$ \\
\hline SSS & $29.36 \pm 0.17$ & $30.33 \pm 0.09$ & $32.08 \pm 0.60$ & $33.86 \pm 0.17$ & $34.84 \pm 0.01$ & $34.17 \pm 0.03$ & $35.43 \pm 0.07$ \\
\hline SUS & $43.06 \pm 0.12$ & $45.00 \pm 0.24$ & $42.41 \pm 0.05$ & $42.49 \pm 0.22$ & $39.51 \pm 0.03$ & $41.41 \pm 0.33$ & $39.94 \pm 0.17$ \\
\hline SUU & $22.38 \pm 0.07$ & $19.43 \pm 0.26$ & $20.51 \pm 0.39$ & $18.65 \pm 0.16$ & $20.35 \pm 0.04$ & $19.41 \pm 0.13$ & $19.24 \pm 0.18$ \\
\hline UUU & $5.20 \pm 0.02$ & $4.99 \pm 0.09$ & $5.01 \pm 0.06$ & $5.01 \pm 0.08$ & $5.30 \pm 0.09$ & $5.01 \pm 0.16$ & $5.39 \pm 0.16$ \\
\hline
\end{tabular}

Note: M - myristic, P - palmitic, S - stearic, O - oleic, L - linoleic, SSS - trisaturated, SUS - disaturated, SUU - monosaturated, UUU - triunsaturated.

Each value in the table represents the mean \pm standard deviation of triplicate analyses $(n=3)$.

TABLE 2. FATTY ACID COMPOSITION, IODINE VALUES AND DROPPING POINTS OF PALM OIL-BASED SOLID FRACTIONS OF PPP 1 WITH $20 \%$ TO $30 \%$ OF PPP CONTENT

\begin{tabular}{|c|c|c|c|c|c|c|c|}
\hline & 1 & 2 & 3 & 4 & 5 & 6 & 7 \\
\hline \multicolumn{8}{|l|}{ Fatty Acids } \\
\hline C 12:0 & $0.19 \pm 0.00$ & $0.16 \pm 0.00$ & $0.17 \pm 0.00$ & $0.38 \pm 0.00$ & $0.17 \pm 0.00$ & $0.22 \pm 0.00$ & $0.12 \pm 0.00$ \\
\hline C 14:0 & $1.22 \pm 0.01$ & $1.30 \pm 0.00$ & $1.34 \pm 0.00$ & $1.43 \pm 0.00$ & $1.26 \pm 0.00$ & $1.33 \pm 0.00$ & $1.24 \pm 0.01$ \\
\hline C 16:0 & $58.98 \pm 0.06$ & $60.58 \pm 0.01$ & $60.69 \pm 0.04$ & $62.39 \pm 0.02$ & $61.56 \pm 0.05$ & $61.63 \pm 0.01$ & $62.99 \pm 0.06$ \\
\hline C $16: 1$ & $0.12 \pm 0.01$ & $0.11 \pm 0.01$ & $0.12 \pm 0.00$ & $0.10 \pm 0.00$ & $0.10 \pm 0.00$ & $0.12 \pm 0.01$ & $0.10 \pm 0.00$ \\
\hline C 18:0 & $5.21 \pm 0.02$ & $5.07 \pm 0.01$ & $4.94 \pm 0.00$ & $4.70 \pm 0.01$ & $5.17 \pm 0.01$ & $4.99 \pm 0.00$ & $4.67 \pm 0.00$ \\
\hline C 18:1 & $27.22 \pm 0.01$ & $26.67 \pm 0.01$ & $26.43 \pm 0.01$ & $24.97 \pm 0.00$ & $25.31 \pm 0.04$ & $25.89 \pm 0.01$ & $25.02 \pm 0.01$ \\
\hline C $18: 2$ & $6.37 \pm 0.01$ & $5.40 \pm 0.01$ & $5.62 \pm 0.01$ & $5.40 \pm 0.00$ & $5.79 \pm 0.01$ & $5.08 \pm 0.00$ & $5.22 \pm 0.05$ \\
\hline C 18:3 & $0.19 \pm 0.01$ & $0.16 \pm 0.01$ & $0.15 \pm 0.01$ & $0.10 \pm 0.16$ & $0.09 \pm 0.00$ & $0.15 \pm 0.00$ & $0.10 \pm 0.00$ \\
\hline C 20:0 & $0.34 \pm 0.01$ & $0.37 \pm 0.00$ & $0.34 \pm 0.01$ & $0.33 \pm 0.00$ & $0.35 \pm 0.00$ & $0.35 \pm 0.00$ & $0.35 \pm 0.00$ \\
\hline Saturated & $65.95 \pm 0.05$ & $67.45 \pm 0.02$ & $67.49 \pm 0.05$ & $69.23 \pm 0.01$ & $68.51 \pm 0.05$ & $68.53 \pm 0.01$ & $69.36 \pm 0.07$ \\
\hline Monounsaturated & $27.34 \pm 0.00$ & $26.77 \pm 0.02$ & $26.54 \pm 0.01$ & $25.07 \pm 0.00$ & $25.41 \pm 0.02$ & $26.01 \pm 0.00$ & $25.12 \pm 0.02$ \\
\hline Polyunsaturated & $6.56 \pm 0.02$ & $5.56 \pm 0.01$ & $5.77 \pm 0.01$ & $5.50 \pm 0.01$ & $5.89 \pm 0.02$ & $5.23 \pm 0.00$ & $5.32 \pm 0.05$ \\
\hline Iodine value $\left(\mathrm{I}_{2} / 100 \mathrm{~g}\right)$ & $34.48 \pm 0.11$ & $33.14 \pm 0.18$ & $32.76 \pm 0.18$ & $32.14 \pm 0.19$ & $32.06 \pm 0.16$ & $31.77 \pm 0.05$ & $31.43 \pm 0.12$ \\
\hline Dropping point $\left({ }^{\circ} \mathrm{C}\right)$ & $54.3 \pm 0.01$ & $54.4 \pm 0.14$ & $54.6 \pm 0.21$ & $55.9 \pm 0.14$ & $56.0 \pm 0.07$ & $55.6 \pm 0.21$ & $56.4 \pm 0.14$ \\
\hline
\end{tabular}

Note: Each value in the table represents the mean \pm standard deviation of triplicate analyses $(n=3)$.

of $20 \%$ to $30 \%$ at $55^{\circ} \mathrm{C}$. The $\mathrm{SFC}$ values were below $1 \%$ at $60^{\circ} \mathrm{C}$ for all samples in Group PPP 2, reflecting the melting of $20 \%$ to $30 \%$ solids from $55^{\circ} \mathrm{C}$ to $60^{\circ} \mathrm{C}$.

\section{POSF of Group PPP 3 with 55\% to $60 \%$ of PPP Content}

POSF in Group PPP 3 were obtained through dry fractionation process of POSF of iodine value 20. The trisaturated triacylglycerols ranged from
$66.78 \%$ to $70.63 \%$ and PPP content contributing $55.70 \%$ to $60.54 \%$ of the POSF as shown in Table 5. The monounsaturated triacylglycerols ranged from $19.22 \%$ to $21.82 \%$, with POP content ranging from $13.95 \%$ to $16.11 \%$. The percentage of diunsaturated and triunsaturated triacylglycerols ranged from $5.23 \%$ to $7.20 \%$ and $3.59 \%$ to $4.80 \%$ respectively. The dropping points of POSF in group PPP 3 were also strongly influenced by the content of trisaturated triacylglycerols as the dropping points recorded for 


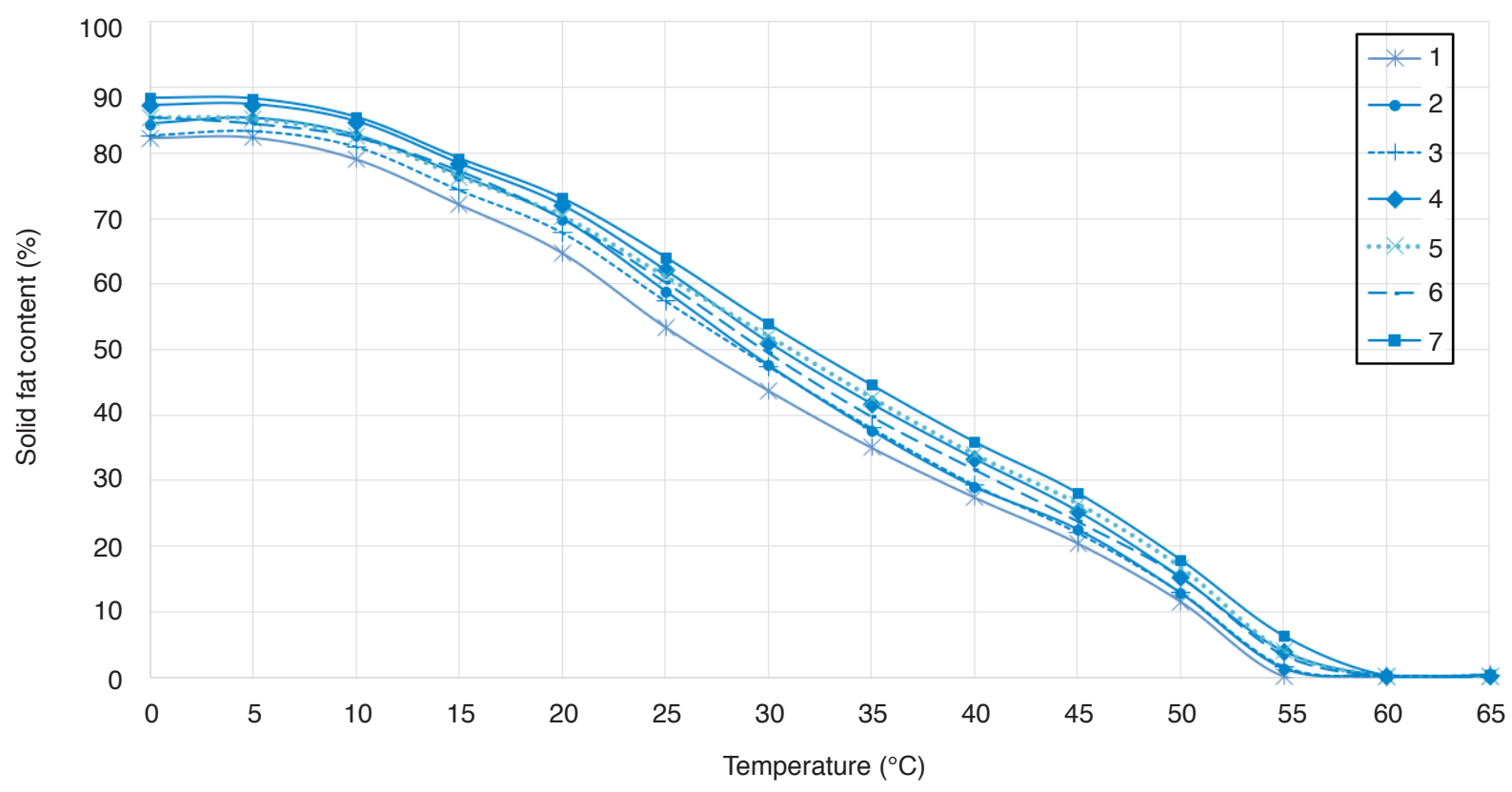

Note: Each value in the table represents the mean \pm standard deviation of triplicate analyses $(n=3)$.

Figure 1. Solid fat content of palm oil-based solid fractions of PPP 1 with $20 \%$ to $30 \%$ of PPP content.

TABLE 3. TRIACYLGLYCEROL COMPOSITION OF PALM OIL-BASED SOLID FRACTIONS OF PPP 2 WITH $40 \%$ TO 50\% OF PPP CONTENT

\begin{tabular}{|c|c|c|c|c|c|c|}
\hline & 1 & 2 & 3 & 4 & 5 & 6 \\
\hline LLL & $0.16 \pm 0.00$ & $0.58 \pm 0.00$ & $0.61 \pm 0.00$ & $0.00 \pm 0.00$ & $0.69 \pm 0.00$ & $0.47 \pm 0.00$ \\
\hline PLL & $0.25 \pm 0.00$ & $0.00 \pm 0.00$ & $0.20 \pm 0.00$ & $0.33 \pm 0.00$ & $0.32 \pm 0.00$ & $0.11 \pm 0.00$ \\
\hline MLP & $0.41 \pm 0.00$ & $0.00 \pm 0.00$ & $0.39 \pm 0.00$ & $0.13 \pm 0.00$ & $0.47 \pm 0.00$ & $0.15 \pm 0.00$ \\
\hline OOL & $0.49 \pm 0.00$ & $0.59 \pm 0.00$ & $0.72 \pm 0.00$ & $0.42 \pm 0.04$ & $0.79 \pm 0.03$ & $0.51 \pm 0.00$ \\
\hline POL & $1.88 \pm 0.00$ & $2.76 \pm 0.00$ & $2.63 \pm 0.07$ & $1.73 \pm 0.04$ & $2.32 \pm 0.00$ & $2.15 \pm 0.00$ \\
\hline PLP & $4.81 \pm 0.00$ & $4.33 \pm 0.00$ & $4.09 \pm 0.01$ & $4.25 \pm 0.07$ & $3.62 \pm 0.00$ & $3.63 \pm 0.04$ \\
\hline MPP & $0.71 \pm 0.00$ & $0.65 \pm 0.00$ & $0.76 \pm 0.00$ & $0.72 \pm 0.04$ & $0.68 \pm 0.00$ & $0.46 \pm 0.00$ \\
\hline $\mathrm{OOO}$ & $3.39 \pm 0.03$ & $4.29 \pm 0.01$ & $4.28 \pm 0.01$ & $3.79 \pm 0.04$ & $4.32 \pm 0.05$ & $4.26 \pm 0.02$ \\
\hline $\mathrm{POO}$ & $4.93 \pm 0.05$ & $6.83 \pm 0.01$ & $7.17 \pm 0.01$ & $3.80 \pm 0.13$ & $6.16 \pm 0.00$ & $5.34 \pm 0.04$ \\
\hline POP & $26.70 \pm .13$ & $20.92 \pm 0.05$ & $19.82 \pm 0.13$ & $23.15 \pm 0.15$ & $17.80 \pm 0.04$ & $18.89 \pm 0.15$ \\
\hline PPP & $42.35 \pm 0.21$ & $44.63 \pm 0.14$ & $45.41 \pm 0.26$ & $47.36 \pm 0.28$ & $48.76 \pm 0.12$ & $48.80 \pm .16$ \\
\hline $\mathrm{SOO}$ & $0.74 \pm 0.00$ & $0.49 \pm 0.00$ & $0.65 \pm 0.00$ & $0.30 \pm 0.03$ & $0.56 \pm 0.00$ & $0.30 \pm 0.00$ \\
\hline POS & $3.97 \pm 0.01$ & $3.21 \pm 0.08$ & $3.087 \pm 0.00$ & $3.04 \pm 0.04$ & $2.92 \pm 0.00$ & $2.52 \pm 0.00$ \\
\hline PPS & $8.02 \pm 0.01$ & $9.45 \pm 0.00$ & $9.074 \pm 0.01$ & $9.57 \pm 0.12$ & $9.47 \pm 0.00$ & $10.61 \pm 0.04$ \\
\hline SOS & $0.27 \pm 0.00$ & $0.0 \pm 0.00$ & $0.00 \pm 0.00$ & $0.31 \pm 0.13$ & $0.00 \pm 0.00$ & $0.34 \pm 0.00$ \\
\hline PSS & $0.92 \pm 0.00$ & $1.22 \pm 0.01$ & $1.05 \pm 0.00$ & $1.11 \pm 0.14$ & $1.04 \pm 0.00$ & $1.47 \pm 0.00$ \\
\hline SSS & $51.99 \pm 0.21$ & $55.97 \pm 0.28$ & $56.30 \pm 0.24$ & $58.76 \pm 0.17$ & $59.96 \pm 0.21$ & $61.34 \pm 0.24$ \\
\hline SUS & $36.17 \pm 0.15$ & $28.46 \pm 0.06$ & $27.39 \pm 0.09$ & $30.88 \pm 0.09$ & $24.84 \pm 0.11$ & $25.53 \pm 0.17$ \\
\hline SUU & $7.80 \pm 0.07$ & $10.08 \pm 0.14$ & $10.67 \pm 0.06$ & $6.15 \pm 0.16$ & $9.37 \pm 0.08$ & $7.89 \pm 0.07$ \\
\hline UUU & $4.04 \pm 0.01$ & $5.47 \pm 0.02$ & $5.63 \pm 0.01$ & $4.21 \pm 0.00$ & $5.81 \pm 0.06$ & $5.24 \pm 0.07$ \\
\hline
\end{tabular}

Note: M - myristic, P - palmitic, S - stearic, O - Oleic, L - linoleic, SSS - trisaturated, SUS - disaturated, SUU - monosaturated,

UUU - triunsaturated.

Each value in the table represents the mean \pm standard deviation of triplicate analyses $(n=3)$.

this group of POSF were in the range of $61.0^{\circ} \mathrm{C}$ to $62.4^{\circ} \mathrm{C}$. The corresponding iodine value obtained were 13.69 to $14.70 \mathrm{I}_{2} / 100 \mathrm{~g}$ as shown in Table 6.

The percentage of saturated fatty acids were the highest ranging from $85.50 \%$ to $86.92 \%$ with $78.43 \%$ to $80.53 \%$ of palmitic acid as shown in Table 6 . The percentage of monounsaturated fatty acids which consist of mostly oleic acid were $10.89 \%$ to $12.10 \%$. The percentage of polyunsaturated fatty acids ranged from $2.10 \%$ to $2.76 \%$.

POSF of Group PPP 3 exhibited high solid fat profiles with readings above $90 \%$ for temperatures below $25^{\circ} \mathrm{C}$. The percentage of solid ranged from $80 \%$ to $90 \%$ between the range of $25^{\circ} \mathrm{C}$ to $35^{\circ} \mathrm{C}$. 
TABLE 4. FATTY ACID COMPOSITION, IODINE VALUES AND DROPPING POINTS OF PALM OIL-BASED SOLID FRACTIONS OF PPP 2 WITH $40 \%$ TO $50 \%$ OF PPP CONTENT

\begin{tabular}{|c|c|c|c|c|c|c|}
\hline & 1 & 2 & 3 & 4 & 5 & 6 \\
\hline \multicolumn{7}{|l|}{ Fatty Acids } \\
\hline C 12:0 & $0.08 \pm 0.00$ & $0.10 \pm 0.00$ & $0.10 \pm 0.00$ & $0.08 \pm 0.02$ & $0.11 \pm 0.00$ & $0.10 \pm 0.00$ \\
\hline C $14: 0$ & $1.33 \pm 0.00$ & $1.42 \pm 0.00$ & $1.35 \pm 0.00$ & $1.45 \pm 0.06$ & $1.35 \pm 0.00$ & $1.52 \pm 0.00$ \\
\hline C $16: 0$ & $73.30 \pm 0.12$ & $72.45 \pm 0.11$ & $72.23 \pm 0.13$ & $76.19 \pm 0.07$ & $74.30 \pm 0.06$ & $74.31 \pm 0.05$ \\
\hline C $16: 1$ & $0.06 \pm 0.00$ & $0.11 \pm 0.09$ & $0.11 \pm 0.07$ & $0.00 \pm 0.00$ & $0.14 \pm 0.00$ & $0.10 \pm 0.00$ \\
\hline C 18:0 & $5.25 \pm 0.00$ & $5.76 \pm 0.11$ & $5.74 \pm 0.01$ & $5.43 \pm 0.09$ & $6.01 \pm 0.00$ & $6.23 \pm 0.00$ \\
\hline C $18: 1$ & $16.39 \pm 0.02$ & $16.19 \pm 0.15$ & $15.91 \pm 0.01$ & $14.74 \pm 0.04$ & $14.12 \pm 0.00$ & $14.11 \pm 0.00$ \\
\hline C $18: 2$ & $3.20 \pm 2.22$ & $3.47 \pm 0.04$ & $3.75 \pm 0.02$ & $2.59 \pm 0.12$ & $3.29 \pm 0.00$ & $3.05 \pm 0.00$ \\
\hline C $18: 3$ & $0.06 \pm 0.00$ & $0.10 \pm 0.00$ & $0.28 \pm 0.10$ & $0.13 \pm 0.05$ & $0.22 \pm 0.00$ & $0.14 \pm 0.00$ \\
\hline C 20:0 & $0.33 \pm 0.00$ & $0.41 \pm 0.00$ & $0.58 \pm 0.00$ & $0.40 \pm 0.05$ & $0.47 \pm 0.00$ & $0.44 \pm 0.00$ \\
\hline Saturated & $80.29 \pm 0.02$ & $80.13 \pm 0.11$ & $80.55 \pm 0.21$ & $83.41 \pm 0.13$ & $82.23 \pm 0.15$ & $82.60 \pm 0.21$ \\
\hline Monounsaturated & $16.45 \pm 0.02$ & $16.30 \pm 0.06$ & $16.02 \pm 0.08$ & $14.74 \pm 0.04$ & $14.26 \pm 0.09$ & $14.21 \pm 0.18$ \\
\hline Polyunsaturated & $3.26 \pm 0.00$ & $3.57 \pm 0.00$ & $3.98 \pm 0.09$ & $2.72 \pm 0.08$ & $3.51 \pm 0.05$ & $3.19 \pm 0.16$ \\
\hline Iodine value $\left(\mathrm{I}_{2} / 100 \mathrm{~g}\right)$ & $20.60 \pm 0.13$ & $20.31 \pm 0.14$ & $20.09 \pm 0.15$ & $20.90 \pm 0.12$ & $18.32 \pm 0.09$ & $17.94 \pm 0.14$ \\
\hline Dropping point $\left({ }^{\circ} \mathrm{C}\right)$ & $59.00 \pm 0.15$ & $59.50 \pm 0.25$ & $60.10 \pm 0.15$ & $60.0 \pm 0.11$ & $60.10 \pm 0.15$ & $60.00 \pm 0.15$ \\
\hline
\end{tabular}

Note: Each value in the table represents the mean \pm standard deviation of triplicate analyses $(n=3)$.

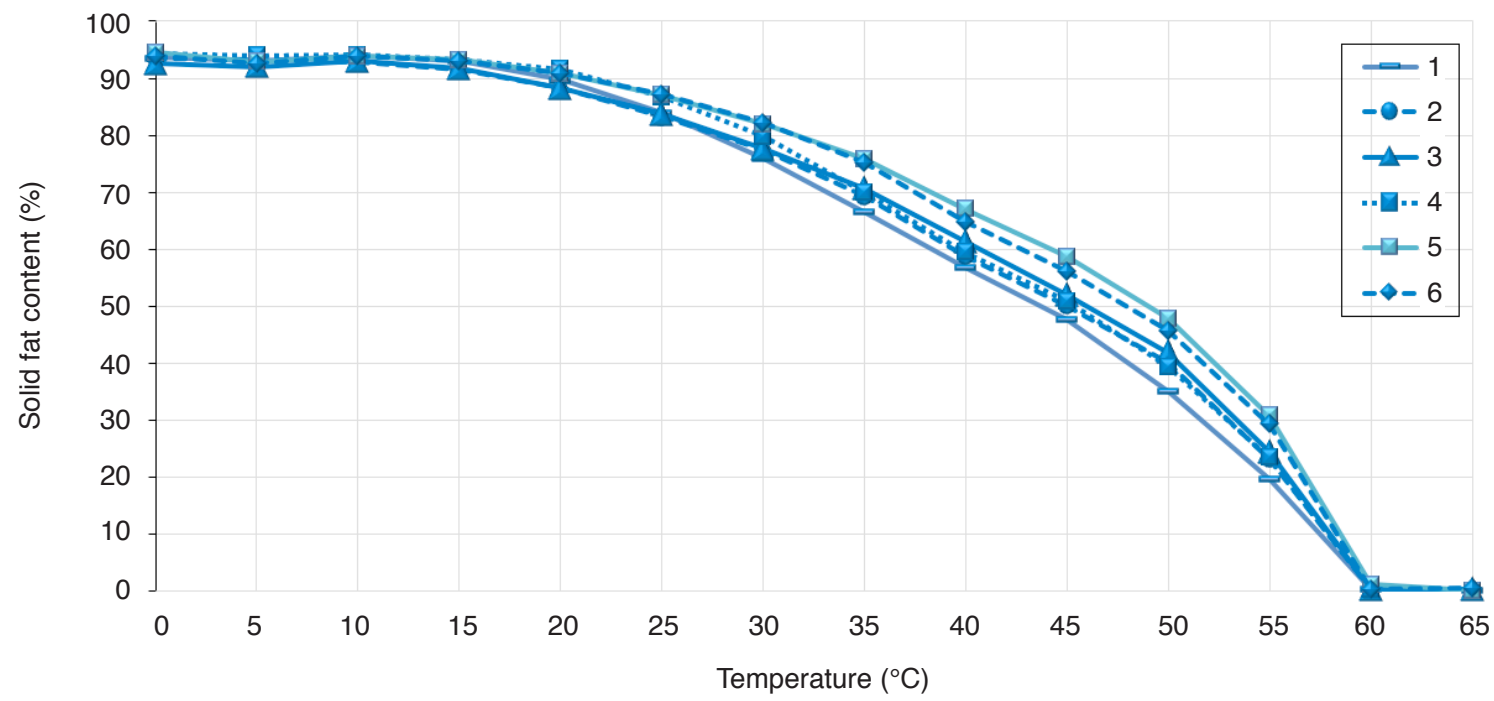

Note: Each value in the table represents the mean \pm standard deviation of triplicate analyses $(n=3)$.

Figure 2. Solid fat content of palm oil-based solid fractions of PPP 2 with $40 \%$ to $50 \%$ of PPP content.

The SFC decreased approximately $7 \%$ to $8 \%$ for the corresponding increase of $10^{\circ} \mathrm{C}$ from $35^{\circ} \mathrm{C}$ to $45^{\circ} \mathrm{C}$ as shown in Figure 3. The SFC from $40 \%$ to $45 \%$ at $55^{\circ} \mathrm{C}$ decreased to $4 \%$ to $13 \%$ at $60^{\circ} \mathrm{C}$ as the fraction experienced a drastic melting of approximately $30 \%$ to $35 \%$ of solids. This drastic drop in SFC was experienced due to the melting of $69 \%$ to $71 \%$ of trisaturated triacylglycerols. The distinctive SFC profile of these POSF qualifies it as an excellent structural fat. This type of POSF was used in the formulation of low saturated fatty acids, margarines and spreads. The required characteristic of the hard palm fraction in this patent was similar to POSF in this group which was to have a SFC of above $75 \%$ at $40^{\circ} \mathrm{C}$, with a corresponding melting point of more than $57^{\circ} \mathrm{C}$ (Ullanoormadam, 2010).

\section{POSF of Group PPP 4 with $62 \%$ to $63 \%$ of PPP content}

POSF in Group PPP 4 were obtained through dry fractionation of POSF of iodine value 20. The trisaturated triacylglycerols ranged from $71.73 \%$ to $74.08 \%$ with PPP contributing $62.23 \%$ to $63.17 \%$ of the POSFs as shown in Table 7. Sample 1 on Table 7 with PPP of $60.59 \%$ was included in this group as this POSF exhibited similar characteristic to Group PPP 4 compared to Group PPP 3. The monounsaturated 
TABLE 5. TRIACYLGLYCEROL COMPOSITION OF PALM OIL-BASED SOLID FRACTIONS OF PPP 3 WITH $55 \%$ TO $60 \%$ OF PPP CONTENT

\begin{tabular}{|c|c|c|c|c|c|c|c|}
\hline & 1 & 2 & 3 & 4 & 5 & 6 & 7 \\
\hline LLL & $0.00 \pm 0.00$ & $0.00 \pm 0.00$ & $0.38 \pm 0.00$ & $0.00 \pm 0.00$ & $0.00 \pm 0.00$ & $0.00 \pm 0.00$ & $0.20 \pm 0.01$ \\
\hline PLL & $0.15 \pm 0.09$ & $0.29 \pm 0.02$ & $0.16 \pm 0.01$ & $0.28 \pm 0.00$ & $0.00 \pm 0.00$ & $0.32 \pm 0.05$ & $0.00 \pm 0.00$ \\
\hline MLP & $0.00 \pm 0.00$ & $0.12 \pm 0.01$ & $0.25 \pm 0.00$ & $0.13 \pm 0.00$ & $0.41 \pm 0.00$ & $0.19 \pm 0.03$ & $0.00 \pm 0.00$ \\
\hline OOL & $0.31 \pm 0.02$ & $0.51 \pm 0.01$ & $0.33 \pm 0.01$ & $0.44 \pm 0.00$ & $0.30 \pm 0.00$ & $0.29 \pm 0.05$ & $0.22 \pm 0.00$ \\
\hline POL & $1.09 \pm 0.06$ & $1.80 \pm 0.04$ & $1.78 \pm 0.01$ & $1.79 \pm 0.00$ & $1.74 \pm 0.01$ & $1.47 \pm 0.04$ & $1.31 \pm 0.00$ \\
\hline PLP & $2.37 \pm 0.04$ & $3.07 \pm 0.22$ & $3.08 \pm 0.03$ & $2.79 \pm 0.00$ & $2.62 \pm 0.01$ & $2.65 \pm 0.11$ & $2.52 \pm 0.00$ \\
\hline MPP & $0.64 \pm 0.00$ & $0.67 \pm 0.10$ & $0.46 \pm 0.00$ & $0.43 \pm 0.00$ & $0.44 \pm 0.00$ & $0.51 \pm 0.01$ & $0.48 \pm 0.01$ \\
\hline OOO & $4.50 \pm 0.06$ & $3.75 \pm 0.04$ & $3.49 \pm 0.00$ & $3.58 \pm 0.01$ & $3.70 \pm 0.01$ & $3.30 \pm 0.12$ & $3.18 \pm 0.00$ \\
\hline POO & $3.68 \pm 0.15$ & $4.10 \pm 0.04$ & $4.92 \pm 0.07$ & $4.74 \pm 0.00$ & $4.62 \pm 0.01$ & $3.93 \pm 0.26$ & $4.16 \pm 0.01$ \\
\hline POP & $16.11 \pm 0.16$ & $14.45 \pm 0.07$ & $16.10 \pm 0.01$ & $15.89 \pm 0.01$ & $13.95 \pm 0.00$ & $14.59 \pm 0.12$ & $15.24 \pm 0.01$ \\
\hline PPP & $55.70 \pm 0.06$ & $56.99 \pm 0.35$ & $56.29 \pm 0.01$ & $57.52 \pm 0.00$ & $58.28 \pm 0.01$ & $59.58 \pm 0.82$ & $60.54 \pm 0.01$ \\
\hline SOO & $0.32 \pm 0.04$ & $0.93 \pm 0.21$ & $0.33 \pm 0.01$ & $0.37 \pm 0.00$ & $0.48 \pm 0.00$ & $0.73 \pm 0.23$ & $0.27 \pm 0.00$ \\
\hline POS & $1.83 \pm 0.11$ & $2.03 \pm 0.03$ & $2.39 \pm 0.01$ & $2.50 \pm 0.00$ & $2.24 \pm 0.00$ & $1.99 \pm 0.14$ & $2.27 \pm 0.00$ \\
\hline PPS & $11.89 \pm .03$ & $10.23 \pm 0.15$ & $9.02 \pm 0.01$ & $8.52 \pm 0.02$ & $10.20 \pm 0.01$ & $9.48 \pm 0.05$ & $8.91 \pm 0.00$ \\
\hline SOS & $0.00 \pm 0.00$ & $0.00 \pm 0.00$ & $0.00 \pm 0.00$ & $0.22 \pm 0.00$ & $0.00 \pm 0.00$ & $0.00 \pm 0.00$ & $0.00 \pm 0.00$ \\
\hline PSS & $1.43 \pm 0.14$ & $1.06 \pm 0.13$ & $1.01 \pm 0.00$ & $0.80 \pm 0.00$ & $1.02 \pm 0.01$ & $0.98 \pm 0.05$ & $0.69 \pm 0.00$ \\
\hline SSS & $69.66 \pm 0.16$ & $68.95 \pm 0.53$ & $66.78 \pm 0.01$ & $67.27 \pm 0.02$ & $69.94 \pm 0.01$ & $70.54 \pm 0.81$ & $70.63 \pm 0.00$ \\
\hline SUS & $20.31 \pm 0.09$ & $19.67 \pm 0.16$ & $21.82 \pm 0.05$ & $21.53 \pm 0.01$ & $19.22 \pm 0.01$ & $19.42 \pm 0.25$ & $20.04 \pm 0.01$ \\
\hline SUU & $5.23 \pm 0.15$ & $7.13 \pm 0.48$ & $7.20 \pm 0.07$ & $7.18 \pm 0.01$ & $6.85 \pm 0.00$ & $6.44 \pm 0.48$ & $5.74 \pm 0.00$ \\
\hline UUU & $4.80 \pm 0.08$ & $4.26 \pm 0.10$ & $4.20 \pm 0.03$ & $4.04 \pm 0.01$ & $4.00 \pm 0.01$ & $3.59 \pm 0.08$ & $3.60 \pm 0.01$ \\
\hline
\end{tabular}

Note: M - myristic, P - palmitic, S - stearic, O - Oleic, L - linoleic, SSS - trisaturated, SUS - disaturated, SUU - monosaturated, UUU - triunsaturated.

Each value in the table represents the mean \pm standard deviation of triplicate analyses $(n=3)$.

TABLE 6. FATTY ACID COMPOSITION, IODINE VALUES AND DROPPING POINTS OF PALM OIL-BASED SOLID FRACTIONS OF PPP 3 WITH 55\% TO 60\% OF PPP CONTENT

\begin{tabular}{|c|c|c|c|c|c|c|c|}
\hline & 1 & 2 & 3 & 4 & 5 & 6 & 7 \\
\hline \multicolumn{8}{|l|}{ Fatty Acids } \\
\hline C 12:0 & $0.16 \pm 0.00$ & $0.80 \pm 0.00$ & $0.10 \pm 0.00$ & $0.23 \pm 0.00$ & $0.10 \pm 0.00$ & $0.07 \pm 0.00$ & $0.10 \pm 0.00$ \\
\hline C 14:0 & $1.70 \pm 0.00$ & $1.55 \pm 0.00$ & $1.10 \pm 0.00$ & $1.21 \pm 0.00$ & $1.30 \pm 0.00$ & $1.20 \pm 0.01$ & $1.10 \pm 0.00$ \\
\hline C 16:0 & $78.43 \pm 0.17$ & $78.32 \pm 0.19$ & $79.30 \pm 0.10$ & $79.86 \pm 0.15$ & $79.50 \pm 0.23$ & $80.53 \pm 0.18$ & $79.70 \pm 0.16$ \\
\hline C 16:1 & $0.02 \pm 0.03$ & $0.05 \pm 0.01$ & $0.20 \pm 0.00$ & $0.20 \pm 0.00$ & $0.20 \pm 0.00$ & $0.14 \pm 0.00$ & $0.10 \pm 0.00$ \\
\hline C 18:0 & $6.09 \pm 0.03$ & $5.46 \pm 0.02$ & $4.80 \pm 0.01$ & $4.51 \pm 0.01$ & $5.10 \pm 0.01$ & $4.85 \pm 0.00$ & $4.80 \pm 0.01$ \\
\hline C 18:1 & $12.26 \pm 0.07$ & $10.97 \pm 0.01$ & $11.90 \pm 0.08$ & $11.48 \pm 0.04$ & $11.40 \pm 0.02$ & $10.75 \pm 0.06$ & $11.90 \pm 0.04$ \\
\hline C 18:2 & $2.76 \pm 0.02$ & $2.34 \pm 0.06$ & $2.40 \pm 0.09$ & $2.09 \pm 0.01$ & $2.20 \pm 0.01$ & $2.10 \pm 0.01$ & $2.10 \pm 0.01$ \\
\hline C 18:3 & $0.00 \pm 0.00$ & $0.00 \pm 0.00$ & $0.00 \pm 0.00$ & $0.00 \pm 0.00$ & $0.00 \pm 0.00$ & $0.00 \pm 0.00$ & $0.00 \pm 0.00$ \\
\hline C 20:0 & $0.36 \pm 0.00$ & $0.29 \pm 0.01$ & $0.20 \pm 0.00$ & $0.21 \pm 0.00$ & $0.20 \pm 0.00$ & $0.28 \pm 0.00$ & $0.10 \pm 0.00$ \\
\hline Saturated & $86.70 \pm 0.14$ & $86.42 \pm 0.21$ & $85.50 \pm 0.12$ & $86.02 \pm 0.18$ & $86.20 \pm 0.24$ & $86.92 \pm 0.19$ & $85.80 \pm 0.18$ \\
\hline Monounsaturated & $12.28 \pm 0.04$ & $11.02 \pm 0.07$ & $12.10 \pm 0.08$ & $11.68 \pm 0.09$ & $11.60 \pm 0.02$ & $10.89 \pm 0.06$ & $12.00 \pm 0.00$ \\
\hline Polyunsaturated & $2.76 \pm 0.02$ & $2.34 \pm 0.06$ & $2.40 \pm 0.09$ & $2.09 \pm 0.01$ & $2.20 \pm 0.00$ & $2.10 \pm 0.01$ & $2.10 \pm 0.00$ \\
\hline Iodine value $\left(\mathrm{I}_{2} / 100 \mathrm{~g}\right)$ & $14.01 \pm 0.17$ & $13.97 \pm 0.12$ & $14.7 \pm 0.15$ & $13.85 \pm 0.24$ & $13.88 \pm 0.18$ & $13.69 \pm 0.10$ & $14.1 \pm 0.22$ \\
\hline Dropping point $\left({ }^{\circ} \mathrm{C}\right)$ & $61.40 \pm 0.25$ & $61.0 \pm 0.15$ & $61.70 \pm 0.20$ & $62.35 \pm 0.15$ & $62.25 \pm 0.25$ & $62.30 \pm 0.20$ & $62.25 \pm 0.30$ \\
\hline
\end{tabular}

Note: Each value in the table represents the mean \pm standard deviation of triplicate analyses $(n=3)$.

triacylglycerols were approximately $14.31 \%$ to $17.73 \%$ with POP content of $11.01 \%$ to $13.02 \%$. The percentage of diunsaturated and triunsaturated triacylglycerol ranged from $5.73 \%$ to $6.74 \%$ and $3.35 \%$ to $4.47 \%$ respectively. The dropping points of the POSF in Group PPP 4 were also strongly influenced by the content of trisaturated triacylglycerols as the dropping points recorded for this group of POSF were in the range of $62.2^{\circ} \mathrm{C}$ to $63.0^{\circ} \mathrm{C}$. The corresponding iodine value obtained were from 11.76 to $11.98 \mathrm{~g}$ of $\mathrm{I}_{2} / 100 \mathrm{~g}$ of oil as shown in Table 8.

The percentage of saturated fatty acids were the highest amounting to $87.86 \%$ to $88.86 \%$ with $81.44 \%$ to $82.80 \%$ of palmitic acid as shown in Table 8 . The percentage of monounsaturated fatty acids which consist of mostly oleic acid was $8.78 \%$ to $10.20 \%$. The percentage of polyunsaturated fatty acids were 


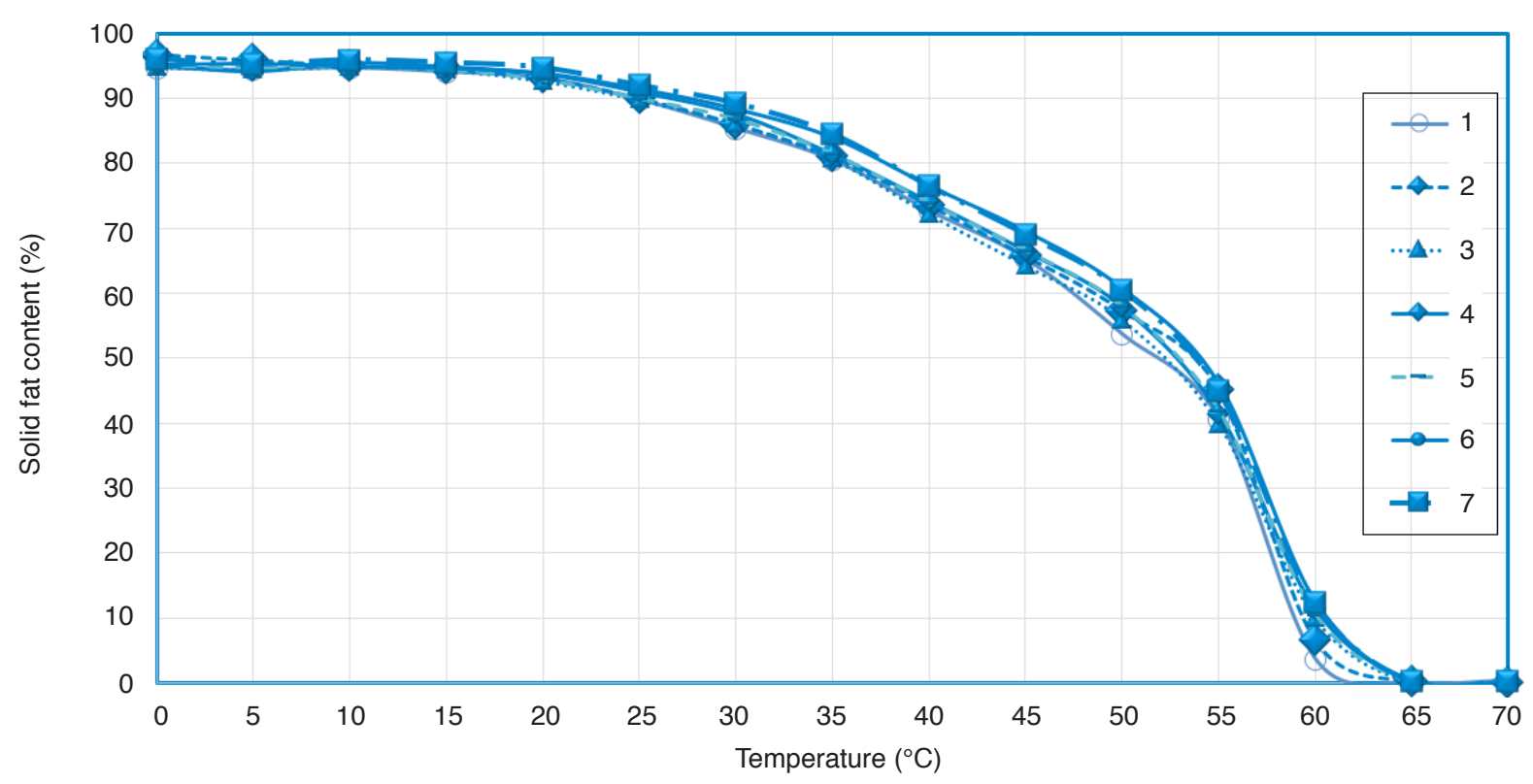

Note: Each value in the table represents the mean \pm standard deviation of triplicate analyses $(n=3)$.

Figure 3. Solid fat content of palm oil-based solid fractions of PPP 3 with $55 \%$ to $60 \%$ of PPP content.

TABLE 7. TRIACYLGLYCEROL COMPOSITION OF PALM OIL-BASED SOLID FRACTIONS OF PPP 4 WITH $62 \%$ TO $63 \%$ OF PPP CONTENT

\begin{tabular}{lcccc}
\hline & $\mathbf{1}$ & $\mathbf{2}$ & $\mathbf{3}$ & $\mathbf{4}$ \\
\hline LLL & $0.33 \pm 0.31$ & $0.00 \pm 0.00$ & $0.00 \pm 0.00$ & $0.6 \pm 0.005$ \\
PLL & $0.40 \pm 0.08$ & $0.23 \pm 0.06$ & $0.24 \pm 0.00$ & $0.54 \pm 0.00$ \\
MLP & $0.07 \pm 0.10$ & $0.12 \pm 0.07$ & $0.00 \pm 0.00$ & $0.70 \pm 0.00$ \\
OOL & $0.45 \pm 0.14$ & $0.38 \pm 0.13$ & $0.29 \pm 0.00$ & $0.57 \pm 0.00$ \\
POL & $1.66 \pm 0.14$ & $1.70 \pm 0.15$ & $1.47 \pm 0.00$ & $1.28 \pm 0.00$ \\
PLP & $2.48 \pm 0.06$ & $2.16 \pm 0.26$ & $2.46 \pm 0.00$ & $2.28 \pm 0.00$ \\
MPP & $0.53 \pm 0.01$ & $0.48 \pm 0.16$ & $0.33 \pm 0.00$ & $0.56 \pm 0.00$ \\
OOO & $3.54 \pm 0.07$ & $3.34 \pm 0.06$ & $3.06 \pm 0.00$ & $3.24 \pm 0.00$ \\
POO & $3.98 \pm 0.49$ & $3.82 \pm 0.34$ & $4.03 \pm 0.00$ & $3.47 \pm 0.00$ \\
POP & $13.02 \pm 0.42$ & $13.06 \pm 0.49$ & $12.94 \pm 0.00$ & $11.01 \pm 0.00$ \\
PPP & $60.59 \pm 0.53$ & $62.23 \pm 1.64$ & $63.05 \pm 0.00$ & $63.17 \pm 0.00$ \\
SOO & $0.70 \pm 0.10$ & $0.45 \pm 0.02$ & $0.53 \pm 0.00$ & $0.4 \pm 0.003$ \\
POS & $1.65 \pm 0.12$ & $1.81 \pm 0.10$ & $1.57 \pm 0.00$ & $0.32 \pm 0.00$ \\
PPS & $9.76 \pm 0.01$ & $9.41 \pm 0.19$ & $9.05 \pm 0.00$ & $9.19 \pm 0.00$ \\
SOS & $0.00 \pm 0.00$ & $0.00 \pm 0.00$ & $0.00 \pm 0.00$ & $0.00 \pm 0.00$ \\
PSS & $0.85 \pm 0.03$ & $0.82 \pm 0.03$ & $0.99 \pm 0.00$ & $1.16 \pm 0.00$ \\
SSS & $71.73 \pm 0.58$ & $72.94 \pm 0.15$ & $73.42 \pm 0.00$ & $74.08 \pm 0.00$ \\
SUS & $17.22 \pm 0.59$ & $17.15 \pm 0.11$ & $16.96 \pm 0.00$ & $14.31 \pm 0.00$ \\
SUU & $6.74 \pm 0.37$ & $6.20 \pm 0.17$ & $6.27 \pm 0.00$ & $5.73 \pm 0.00$ \\
UUU & $4.31 \pm 0.38$ & $3.71 \pm 0.07$ & $3.35 \pm 0.00$ & $4.47 \pm 0.00$ \\
\hline
\end{tabular}

Note: M - myristic, P - palmitic, S - stearic, O - oleic, L - linoleic, SSS - trisaturated, SUS - disaturated, SUU - monosaturated, UUU - triunsaturated.

approximately $1.81 \%$ to $2.04 \%$. These type of POSF were used to produce exclusive structural fats for margarine formulations with low SAFA (saturated fatty acids). The margarine fat blend consisted of $93 \%$ of sunflower oil and a mere $7 \%$ of this structural fat to achieve the required texture and firmness of the product. The double fractionated trans-free (nonhydrogenated) palm fraction used in the production of this structural fat had approximately $81 \%$ of palmitic acid which contributed to the formation of the firm crystal matrix (Ullanoormadam, 2009).

POSF of Group PPP 4 exhibited higher SFC profiles as compared to PPP1, PPP 2 and PPP 3 between the temperatures of $0^{\circ} \mathrm{C}$ to $65^{\circ} \mathrm{C}$. POSF of group PPP 4 exhibited high SFC profiles with above $90 \%$ for temperatures below $30^{\circ} \mathrm{C}$ as shown in Figure 4. The percentage of SFC ranged from $80 \%$ to $90 \%$ between temperatures of $30^{\circ} \mathrm{C}$ to $40^{\circ} \mathrm{C}$. 
The percentage of SFC decreased from $80 \%$ to $70 \%$ between temperatures of $40^{\circ} \mathrm{C}$ to $50^{\circ} \mathrm{C}$. The $\mathrm{SFC}$ from $50 \%$ to $52 \%$ at $55^{\circ} \mathrm{C}$ and decreased to $15 \%$ to $20 \%$ at $60^{\circ} \mathrm{C}$. The SFC decreased by approximately $35 \%$ between the temperatures of $55^{\circ} \mathrm{C}$ to $60^{\circ} \mathrm{C}$. The SFC of the fractions were below $1 \%$ at $65^{\circ} \mathrm{C}$, experiencing a drop of $15 \%$ to $20 \%$ of solids from $60^{\circ} \mathrm{C}$ to $65^{\circ} \mathrm{C}$.

\section{POSF of Group PPP 5 with $67 \%$ to $68 \%$ of PPP Content}

POSF in Group PPP 5 were obtained through fractionation of POSF of iodine value 20. The percentage of diunsaturated and triunsaturated triacylglycerol ranged from $4.06 \%$ to $5.34 \%$ and $3.19 \%$ to $3.23 \%$. The monounsaturated triacylglycerols were $13.91 \%$ to $14.55 \%$ with POP content of $10.21 \%$ to $10.91 \%$. The trisaturated triacylglycerols ranged from $77.46 \%$ to $78.21 \%$ with $67.23 \%$ to $67.67 \%$ of PPP content as shown in Table 9. These POSF are potential source of tripalmitin, which is used to produce human milk fat replacer for infant formulations (Son et al., 2010; Lee et al., 2015; Maduko et al., 2007; Mukherjee and Kiewitt, 1998). The dropping points of the POSF in Group PPP 5 were also strongly influenced by trisaturated triacylglycerol content as the dropping points recorded for this group of POSF were in the range of $63^{\circ} \mathrm{C}$ to $64^{\circ} \mathrm{C}$. The corresponding IV obtained were approximates 9.64 to $10.10 \mathrm{I}_{2} / 100 \mathrm{~g}$ of oil as indicated in Table 10. The results also show the percentage of saturated fatty acids were the highest with approximately $89.73 \%$ to $90.54 \%$ with $84.38 \%$ to $84.735 \%$ of palmitic acid as shown in Table 10 . Whilst, the percentage of monounsaturated fatty acids which consist of mostly of oleic acid were $7.87 \%$ to $8.38 \%$. The percentage of polyunsaturated fatty acids is approximately $1.49 \%$ to $1.60 \%$.

POSF of Group PPP 5 exhibited higher SFC profiles as compared to PPP 1, PPP 2, PPP 3 and PPP 4 between the temperatures of $0^{\circ} \mathrm{C}$ to $65^{\circ} \mathrm{C}$. POSF of Group PPP 5 exhibited high solid fat profiles with readings above $90 \%$ for temperatures below $30^{\circ} \mathrm{C}$ as shown in Figure 5. The percentage of SFC decreased $7 \%$ with the increase of $5^{\circ} \mathrm{C}$ between the temperatures of $40^{\circ} \mathrm{C}$ to $50^{\circ} \mathrm{C}$. The percentage of SFC decreased from $84 \%$ to $70 \%$ between the temperatures of $40^{\circ} \mathrm{C}$ to $50^{\circ} \mathrm{C}$. The SFC from $57 \%$ to $59 \%$ at $55^{\circ} \mathrm{C}$ decreased to $27 \%$ to $29 \%$ at $60^{\circ} \mathrm{C}$. The SFC decreased by approximately $30 \%$ between the temperatures of $55^{\circ} \mathrm{C}$ to $60^{\circ} \mathrm{C}$. The SFC of the fractions were below $1 \%$ at $65^{\circ} \mathrm{C}$, experiencing a drop of $27 \%$ to $29 \%$ of solids from $60^{\circ} \mathrm{C}$ to $65^{\circ} \mathrm{C}$. These fractions were totally melted above $65^{\circ} \mathrm{C}$.

\section{CONCLUSION}

Natural and trans fatty acids free solid fats are in great demand for food formulations as the consumer market is increasingly driven by this preference. POSF have this advantage as these fractions are natural, trans fatty acids free and has the additional advantage of being cholesterol free as they are of vegetable oil origin. This compilation of this physical and chemical characteristics of POSF which contains more than $20 \%$ of PPP from Malaysian fractionation plants will provide a basic but nevertheless crucial information required by high fat food formulators. The characteristics of the POSF were greatly influenced by the

TABLE 8. FATTY ACID COMPOSITION, IODINE VALUES AND DROPPING POINTS OF PALM OIL-BASED SOLID FRACTIONS OF PPP 4 WITH $62 \%$ TO $63 \%$ OF PPP CONTENT

\begin{tabular}{lcccc}
\hline & 1 & 2 & 3 & 4 \\
\hline Fatty Acids & & & & \\
C 12:0 & $0.06 \pm 0.00$ & $0.06 \pm 0.00$ & $0.11 \pm 0.00$ & $0.1 \pm 0.00$ \\
C 14:0 & $1.25 \pm 0.01$ & $1.13 \pm 0.00$ & $1.02 \pm 0.00$ & $1.09 \pm 0.00$ \\
C 16:0 & $81.44 \pm 0.03$ & $81.66 \pm 0.02$ & $82.80 \pm 0.09$ & $82.12 \pm 0.00$ \\
C 16:1 & $0.15 \pm 0.00$ & $0.00 \pm 0.02$ & $0.20 \pm 0.00$ & $0.11 \pm 0.00$ \\
C 18:0 & $4.83 \pm 0.03$ & $4.78 \pm 0.00$ & $4.38 \pm 0.01$ & $5.23 \pm 0.00$ \\
C 18:1 & $9.87 \pm 0.03$ & $9.91 \pm 0.00$ & $9.59 \pm 0.03$ & $8.67 \pm 0.00$ \\
C 18:2 & $2.04 \pm 0.05$ & $1.98 \pm 0.01$ & $1.73 \pm 0.00$ & $2.02 \pm 0.00$ \\
C 18:3 & $0.00 \pm 0.00$ & $0.00 \pm 0.00$ & $0.18 \pm 0.00$ & $0.12 \pm 0.00$ \\
C 20:0 & $0.27 \pm 0.00$ & $0.25 \pm 0.00$ & $0.00 \pm 0.00$ & $0.32 \pm 0.00$ \\
Saturated & $87.86 \pm 0.08$ & $87.89 \pm 0.01$ & $88.33 \pm 0.10$ & $88.86 \pm 0.00$ \\
Monounsaturated & $10.02 \pm 0.03$ & $9.91 \pm 0.01$ & $9.79 \pm 0.03$ & $8.78 \pm 0.00$ \\
Polyunsaturated & $2.04 \pm 0.05$ & $1.98 \pm 0.00$ & $1.81 \pm 0.00$ & $2.14 \pm 0.00$ \\
Iodine value $\left(\mathrm{I}_{2} / 100 \mathrm{~g}\right)$ & $11.98 \pm 0.11$ & $11.78 \pm 0.21$ & $11.76 \pm 0.00$ & $11.98 \pm 0.00$ \\
Dropping point $\left({ }^{\circ} \mathrm{C}\right)$ & $62.2 \pm 0.25$ & $62.3 \pm 0.25$ & $62.95 \pm 0.15$ & $62.40 \pm 0.25$ \\
\hline
\end{tabular}

Note: Each value in the table represents the mean \pm standard deviation of triplicate analyses $(n=3)$. 


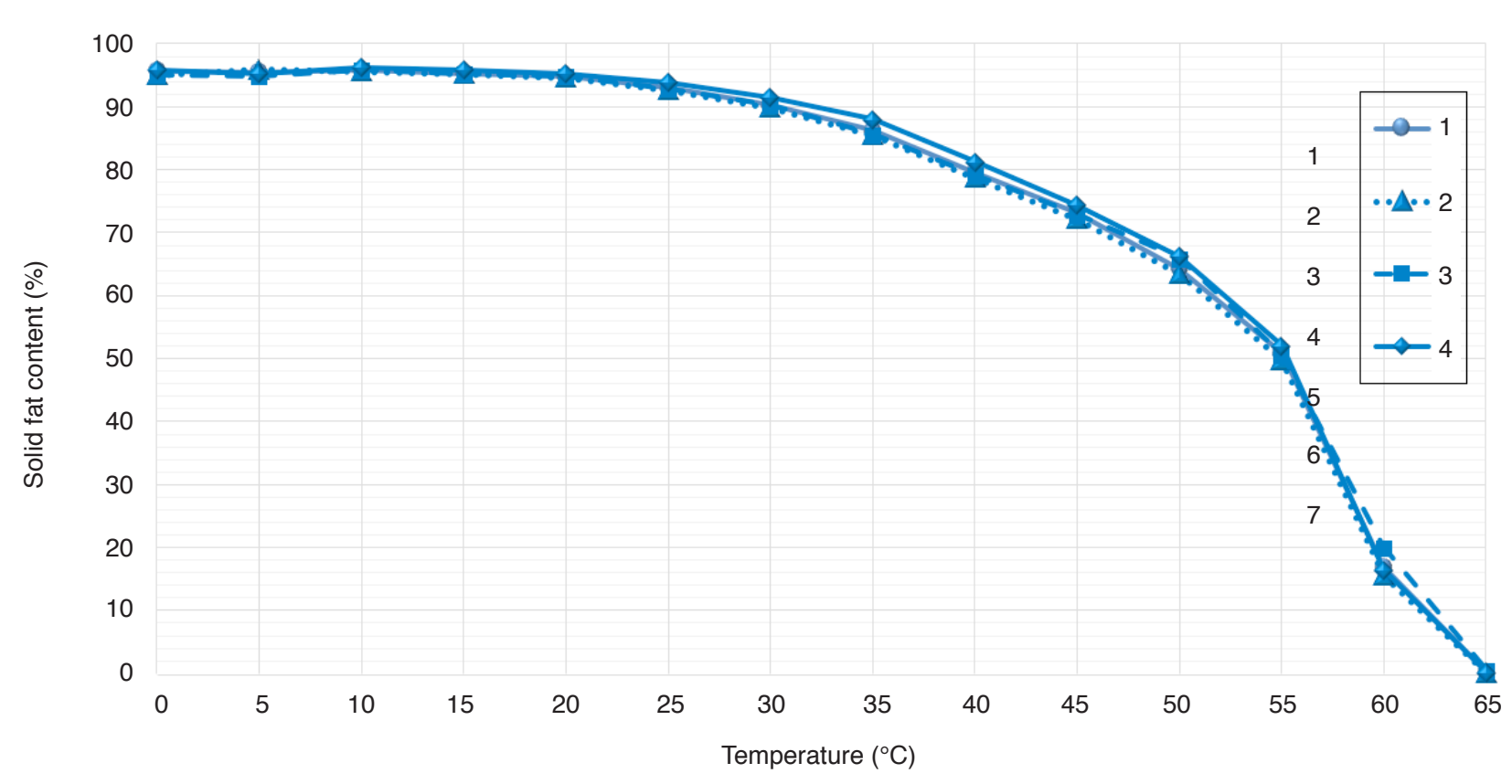

Note: Each value in the table represents the mean \pm standard deviation of triplicate analyses $(n=3)$.

Figure 4. Solid fat content of palm oil-based solid fractions of PPP 4 with $62 \%$ to $63 \%$ of PPP content.

TABLE 9. TRIACYLGLYCEROL COMPOSITION OF PALM OIL-BASED SOLID FRACTIONS OF PPP 5 WITH $67 \%$ TO $68 \%$ OF PPP CONTENT

\begin{tabular}{lccc}
\hline & $\mathbf{1}$ & $\mathbf{2}$ & $\mathbf{3}$ \\
\hline LLL & $0.00 \pm 0.00$ & $0.07 \pm 0.00$ & $0.00 \pm 0.00$ \\
PLL & $0.16 \pm 0.00$ & $0.42 \pm 0.01$ & $0.00 \pm 0.00$ \\
MLP & $0.00 \pm 0.12$ & $0.23 \pm 0.01$ & $0.24 \pm 0.00$ \\
OOL & $0.23 \pm 0.01$ & $0.19 \pm 0.00$ & $0.20 \pm 0.00$ \\
POL & $1.05 \pm 0.00$ & $1.17 \pm 0.00$ & $1.29 \pm 0.00$ \\
PLP & $2.04 \pm 0.04$ & $1.89 \pm 0.00$ & $1.89 \pm 0.00$ \\
MPP & $0.26 \pm 0.02$ & $0.26 \pm 0.00$ & $0.28 \pm 0.02$ \\
OOO & $2.95 \pm 0.05$ & $2.94 \pm 0.00$ & $3.03 \pm 0.00$ \\
POO & $2.68 \pm 0.02$ & $3.30 \pm 0.00$ & $3.81 \pm 0.01$ \\
POP & $10.91 \pm 0.00$ & $10.21 \pm 0.00$ & $10.36 \pm 0.01$ \\
PPP & $67.27 \pm 0.07$ & $67.23 \pm 0.01$ & $67.67 \pm 0.00$ \\
SOO & $0.16 \pm 0.00$ & $0.27 \pm 0.01$ & $0.24 \pm 0.00$ \\
POS & $1.59 \pm 0.07$ & $1.59 \pm 0.01$ & $1.49 \pm 0.01$ \\
PPS & $9.57 \pm 0.10$ & $9.37 \pm 0.01$ & $8.84 \pm 0.00$ \\
SOS & $0.00 \pm 0.00$ & $0.00 \pm 0.00$ & $0.00 \pm 0.00$ \\
PSS & $1.11 \pm 0.01$ & $0.87 \pm 0.00$ & $0.67 \pm 0.01$ \\
SSS & $78.21 \pm 0.05$ & $77.73 \pm 0.01$ & $77.46 \pm 0.01$ \\
SUS & $14.55 \pm 0.03$ & $13.91 \pm 0.00$ & $13.97 \pm 0.01$ \\
SUU & $4.06 \pm 0.02$ & $5.16 \pm 0.01$ & $5.34 \pm 0.01$ \\
UUU & $3.19 \pm 0.06$ & $3.20 \pm 0.00$ & $3.23 \pm 0.00$ \\
\hline
\end{tabular}

Note: M - myristic, P - Palmitic, S - stearic, O - Oleic, L - linoleic, SSS - trisaturated, SUS - disaturated, SUU - monosaturated, UUU - triunsaturated.

Each value in the table represents the mean \pm standard deviation of triplicate analyses $(n=3)$.

triacylglycerol composition which is reflected in the corresponding fatty acid composition, iodine value, dropping point and SFC. The characteristics of POSF were greatly influenced and dominated by the trisaturated triacylglyceroly namely PPP. The increase of PPP increased the dropping points and exhibited high values of SFC in the evaluated POSF. Hence, fractions were categorised according to the percentage of PPP to provide groupings with specific physical and chemical characteristics to assist food formulators. The percentage of PPP in Group PPP 1 was 20\% to 30\%, PPP 2 was $40 \%$ 
TABLE 10. FATTY ACID COMPOSITION, IODINE VALUES AND DROPPING POINTS OF PALM OIL-BASED SOLID FRACTIONS OF PPP 5 WITH $67 \%$ TO 68\% OF PPP CONTENT

\begin{tabular}{lccc}
\hline & $\mathbf{1}$ & $\mathbf{2}$ & $\mathbf{3}$ \\
\hline Fatty Acids & $0.10 \pm 0.00$ & $0.10 \pm 0.00$ & $0.05 \pm 0.00$ \\
C 12:0 & $1.02 \pm 0.00$ & $1.00 \pm 0.00$ & $0.90 \pm 0.00$ \\
C 14:0 & $84.65 \pm 0.19$ & $84.73 \pm 0.21$ & $84.38 \pm 0.15$ \\
C 16:0 & $0.20 \pm 0.00$ & $0.19 \pm 0.00$ & $0.10 \pm 0.00$ \\
C 16:1 & $4.51 \pm 0.00$ & $4.50 \pm 0.00$ & $4.30 \pm 0.00$ \\
C 18:0 & $7.78 \pm 0.09$ & $7.78 \pm 0.04$ & $8.28 \pm 0.00$ \\
C 18:1 & $1.51 \pm 0.00$ & $1.49 \pm 0.00$ & $1.60 \pm 0.00$ \\
C 18:2 & $0.00 \pm 0.00$ & $0.00 \pm 0.00$ & $0.00 \pm 0.00$ \\
C 18:3 & $0.23 \pm 0.00$ & $0.20 \pm 0.00$ & $0.10 \pm 0.00$ \\
C 20:0 & $90.51 \pm 0.19$ & $90.54 \pm 0.21$ & $89.73 \pm 0.15$ \\
Saturated & $7.98 \pm 0.09$ & $7.97 \pm 0.04$ & $8.38 \pm 0.00$ \\
Monounsaturated & $1.51 \pm 0.00$ & $1.49 \pm 0.00$ & $1.60 \pm 0.00$ \\
Polyunsaturated & $9.64 \pm 0.12$ & $9.97 \pm 0.211$ & $10.1 \pm 0.17$ \\
Iodine value $\left(\mathrm{I}_{2} / 100 \mathrm{~g}\right)$ & $63.70 \pm 0.25$ & $63.65 \pm 0.30$ & $63.15 \pm 0.20$ \\
Dropping point $\left({ }^{\circ} \mathrm{C}\right)$ &
\end{tabular}

Note: Each value in the table represents the mean \pm standard deviation of triplicate analyses $(n=3)$.

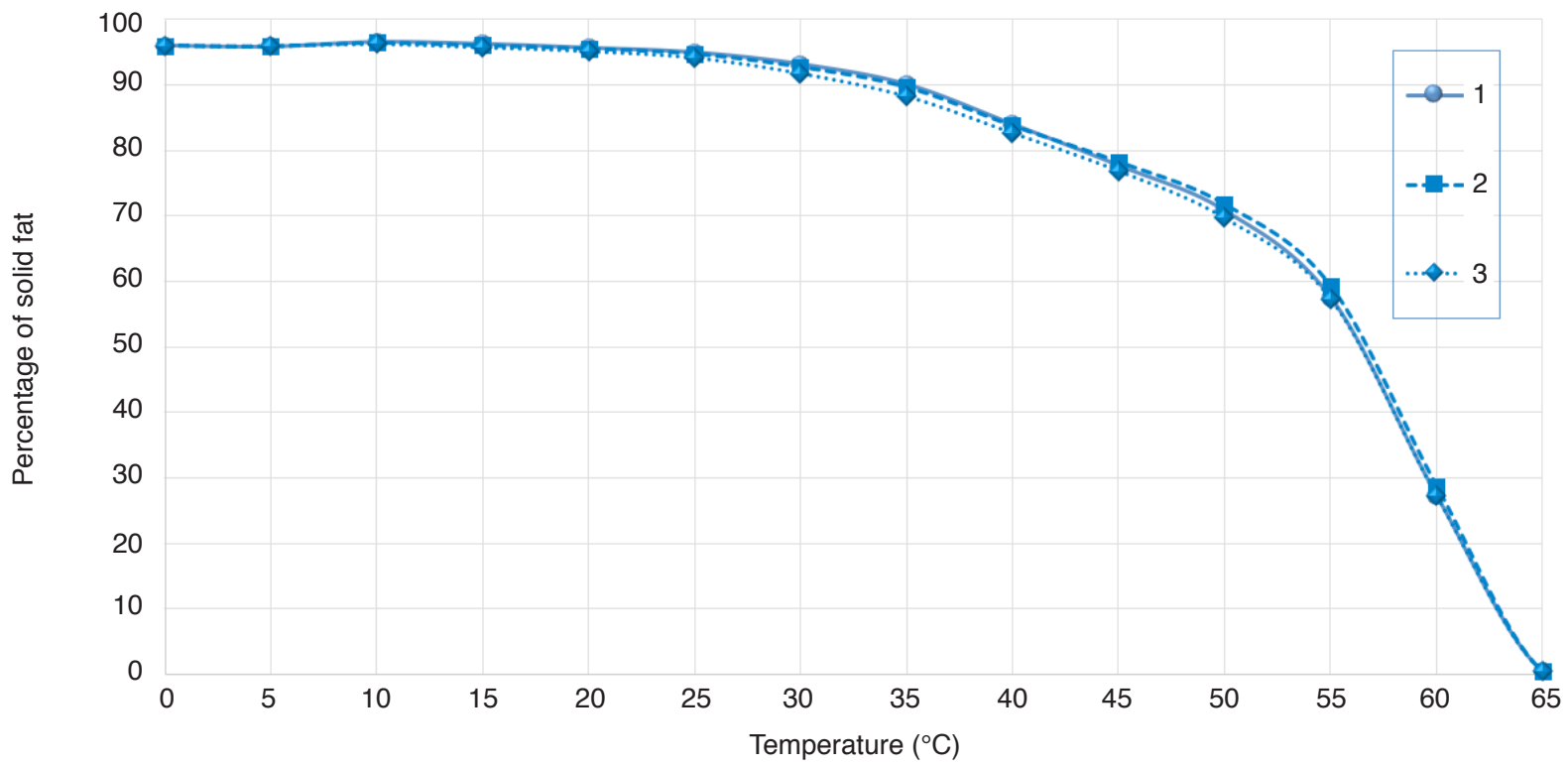

Note: Each value in the table represents the mean \pm standard deviation of triplicate analyses $(n=3)$.

Figure 5. Solid fat content of palm oil-based solid fractions of PPP 5 with $67 \%$ to $68 \%$ of PPP content.

to $50 \%$, PPP 3 was $55 \%$ to $60 \%$, PPP 4 was $62 \%$ to $63 \%$ and PPP 5 was $67 \%$ to $68 \%$. The wide range of commercially available POSF opens great opportunities and diversification of functionality and application of these fractions in high fat food products.

\section{ACKNOWLEDGEMENT}

The authors would like to thank the Director-General of MPOB for permission to publish this article.

\section{REFERENCES}

AHMAD, T A H and ISMAIL, R (2008). Comparison of the frying stability of standard palm olein and special quality palm olein. J. Amer. Oil Chem. Soc., 85: 245-251.

AINI, I; HANIRAH, H; MAIMON, C; ZAWIAH, S and MAN, Y (2010). Physico-chemical properties and quality of palm-based vegetable ghee. Sains Malaysiana, 39: 791-794 
BRAIPSON-DANTHINE, S and GIBON, V (2007). Comparative analysis of triacylglycerol composition, melting properties and polymorphic behavior of palm oil and fractions. European J. Lipid Science and Technology, 109: 359-372.

CALLIAUW, G; GIBON, V; DE GREYT, W; PLEES, L; FOUBERT, I and DEWETTINCK, K (2007). Phase composition during palm olein fractionation and its effect on soft PMF and superolein quality. J. Amer. Oil Chem. Soc., 84: 885-891.

DEFFENSE, E (1985). Fractionation of palm oil. J. Amer. Oil Chem. Soc., 62: 376-385.

FLÖTER, E; BOT, A; WILLIAMS, C and BUTTRISS, J (2006). Developing products with modified fats. Improving the Fat Content of Foods. p. 411-427.

KELLENS, M; GIBON, V; HENDRIX, $M$ and DE GREYT, W (2007). Palm oil fractionation. European J. Lipid Science and Technology, 109: 336-349.

KELLENS, $M$ and HENDRIX, M (2000). Fractionation. Introduction to Fats and Oils Technology. Second ed. AOCS Press. p. 194-207.

KLOEK, W; WALSTRA, P and VAN VLIET, T (2000). Crystallization kinetics of fully hydrogenated palm oil in sunflower oil mixtures. J. Amer. Oil Chem. Soc., 77: 389-398.

KUNTOM, A; SIEW, W L; TAN, Y I; NOR AINI, I and IBRAHIM, N A (2005). MPOB Test Methods. MPOB, Bangi.

LAI, O M; GHAZALI, H M and CHONG, C L (1998). Effect of enzymatic transesterification on the melting points of palm stearin-sunflower oil mixtures. J. Amer. Oil Chem. Soc., 75: 881-886.

LEE, N K; OH, S W; KWON, D Y and YOON, S H (2015). Production of 1, 3-dioleoyl-2-palmitoyl glycerol as a human milk fat substitute using enzymatic interesterification of natural fats and oils. Food Science and Biotechnology, 24: 433-437.

LIU, Y; MENG, Z; ZHANG, F; SHAN, L and WANG, X (2010). Influence of lipid composition, crystallization behavior and microstructure on hardness of palm oil-based margarines. European Food Research and Technology, 230: 759-767.

MADUKO, C O; AKOH, C C and PARK, Y W (2007). Enzymatic interesterification of tripalmitin with vegetable oil blends for formulation of caprine milk infant formula analogs. J. Dairy Science, 90: 594-601.

MARANGONI, A G (2005). The nature of fractility. Fat Crystal Networks. p. 413-440.
MING, L O; GHAZALI, H M and CHIEW, L C (1999). Use of enzymatic transesterified palm stearinsunflower oil blends in the preparation of table margarine formulation. Food Chemistry, 64: 83-88.

MUKHERJEE, K D and KIEWITT, I (1998). Structured triacylglycerols resembling human milk fat by transesterification catalyzed by papaya (Carica papaya) latex. Biotechnology Letters, 20: 613616.

NARINE, SS and MARANGONI, A G (1999). Fractal nature of fat crystal networks. Physical Review E, 59: 1908-1920.

NARINE, S S and MARANGONI, A G (2002). Structure and mechanical properties of fat crystal networks. Advances in Food and Nutrition Research, 44: 33-145.

NORIZZAH, A R; CHONG, C L; CHEOW, C $S$ and ZALIHA, O (2004). Effects of chemical interesterification on physicochemical properties of palm stearin and palm kernel olein blends. Food Chemistry, 86: 229-235.

OKAWACHI, T; SAGI, $\mathrm{N}$ and MORI, H (1985). Confectionery fats from palm oil. J. Amer. Oil Chem. Soc., 62: 421-425.

OMONOV, T S; BOUZIDI, L and NARINE, S S (2010). Quantification of oil binding capacity of structuring fats: A novel method and its application. Chemistry and Physics of Lipids, 163: 728-740.

PANDE, G and AKOH, C C (2013). Enzymatic modification of lipids for trans-free margarine. Lipid Technology, 25: 31-33.

PERNETTI, M; VAN MALSSEN, K F; FLÖTER, E and BOT, A (2007). Structuring of edible oils by alternatives to crystalline fat. Current Opinion in Colloid E Interface Science, 12: 221-231.

RAMLI, $M$ R; SIEW, $W$ L and CHEAH, K Y (2008). Properties of high-oleic palm oils derived by fractional crystallization. J. Food Science, 73: C140-C145.

ROGERS, M A (2009). Novel structuring strategies for unsaturated fats - Meeting the zero-trans, zerosaturated fat challenge: A review. Food Research International, 42: 747-753.

SON, J M; LEE, K T; AKOH, C C; KIM, M R; KIM, M J and LEE, J H (2010). Optimisation of tripalmitin-rich fractionation from palm stearin by response surface methodology. J. Science of Food and Agriculture, 90: 1520-1526. 
ULLANOORMADAM, S R (2004). Trans-free hard structural fat for margarine blend and spreads. US patent, US 6,808,737B2.

ULLANOORMADAM, S R (2009). Trans-free non-hydrogenated hard structural fat and nonhydrogenated hard palm oil fraction component. US patent, US 7,618,670B2.

ULLANOORMADAM, S R (2010). Trans-free hard palm oil fraction, trans, free non-hydrogenated hard structural fat and fat blends and methods. US patent, US 7,807,208B2.

VUILLEQUEZ, A; KOZA, L; YOUSSEF, B; BRIDIER, $M$ and SAITER, J M (2010). Thermal and structural behavior of palm oil. Influence of cooling rate on fat crystallization. Macromolecular Symposia, 290: 137-145.

ZHOU, S L; ZHANG, F Q; JIN, Q Z; LIU, Y F; SHAN, L; ZHANG, T; ZOU, X $Q$ and WANG, X G (2010). Characterization of palm kernel oil, palm stearin, and palm olein blends in isosolid diagrams. European J. Lipid Science and Technology, 112: 10411047.

ZOU, X; JIN, Q; GUO, Z; XU, X and WANG, X (2016). Preparation of human milk fat substitutes from basa catfish oil: Combination of enzymatic acidolysis and modeled blending. European J. Lipid Science and Technology, 118: 1702-1711. 